\title{
ОСОБЕННОСТИ АНТИБАКТЕРИАЛЬНОЙ ТЕРАПИИ В ЛЕЧЕНИИ ОСТРОГО ДЕСТРУКТИВНОГО ПАНКРЕАТИТА
}

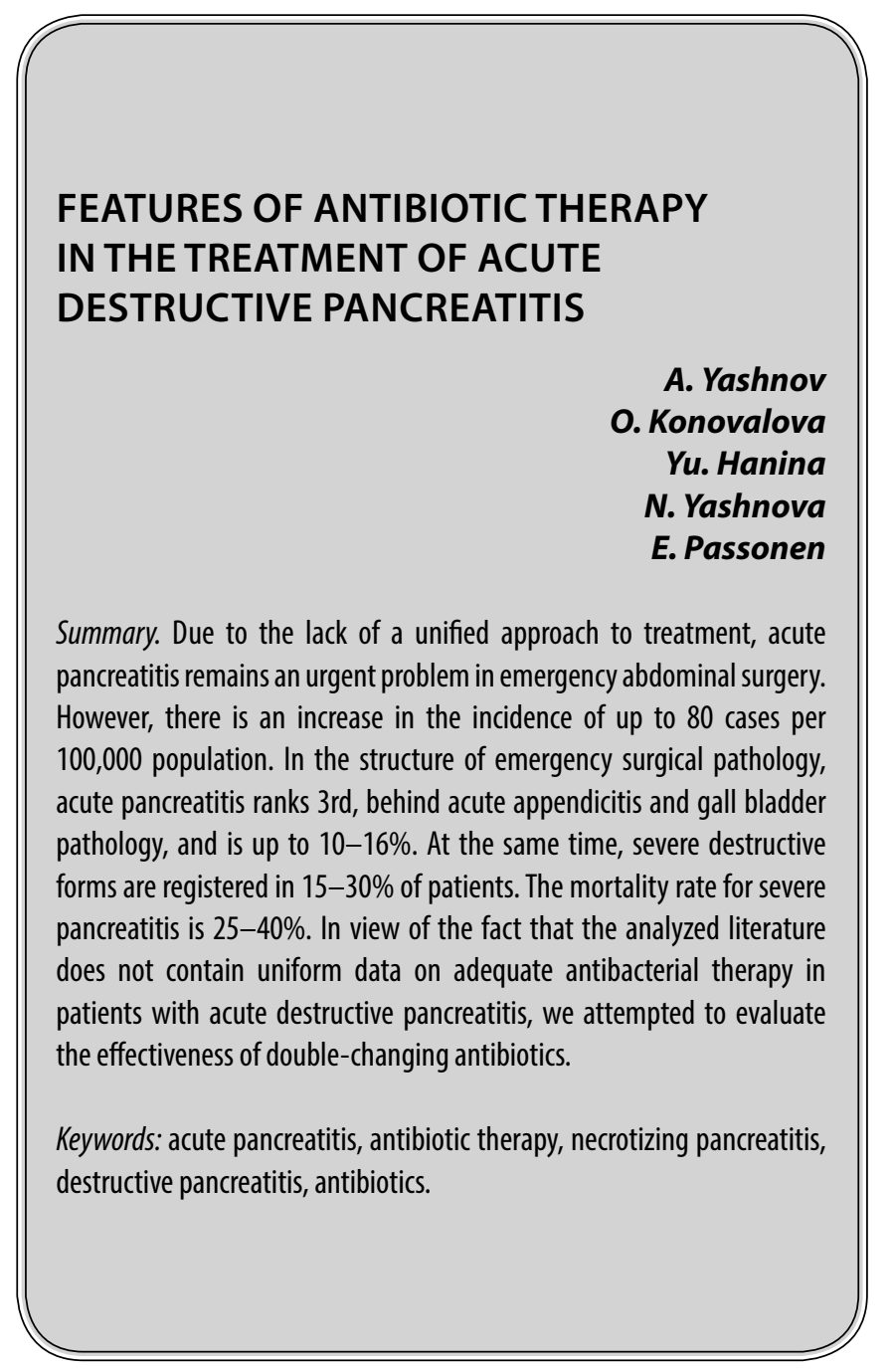

\section{Введение}

B настоящее время острый панкреатит - это наиболее значимая нерешенная проблема современной медицины. По данным разных авторов в течение нескольких лет острый панкреатит занимает третье, а по некоторым регионам - первое место в структуре ургентных хирургических заболеваний, уступая острому аппендициту и патологии желчного пузыря, и составляет до $10-16 \%$. [1,2]. Отмечается увеличение заболеваемости острым панкреатитом до 80 случаев на 100000 населения. При этом у 15-30\% больных регистрируются тяжелые деструктивные формы. Летальность при тяжелом панкреатите составляет 25-40\%. Установлено, что высокий уровень летальности обусловлен многоуровневым патогенезом
Яшнов Алексей Александрович

К.м.н., ассистент, ФГБОУ ВО «Читинская государственная медицинская академия» alexyashnov@mail.ru

Коновалова Ольга Геннадьевна К.м.н., дочент, ФГБОУ ВО «Читинская государственная медицинская академия» konovalovaolgagen@yandex.ru

Ханина Юлия Сергеевна

К.м.н., дочент, ФГБОУ ВО «Читинская государственная медицинская академия» assistenty@yandex.ru

Яшнова Надежда Борисовна ФГБОУ ВО «Читинская государственная медичинская академия»

Пассонен Екатерина Юрьевна ГУз Городская клиническая больница № 1

Аннотация. В связи с отсутствием единого подхода к лечению, острый панкреатит остается актуальной проблемой в неотложной абдоминальной хирургии. Вместе с тем отмечается увеличение заболеваемости до 80 случаев на 100000 населения. В структуре экстренной хирургической патологии острый панкреатит занимает 3 место, уступая острому аппендициту и патологии желчного пузыря, и составляет до 10-16\%. При этом у 15-30\% больных регистрируются тяжелые деструктивные формы. Летальность при тяжелом панкреатите составляет $25-40 \%$. В виду того, что в анализируемой литературе нет единых данных об адекватной антибактериальной терапии у пациентов с острым деструктивным панкреатитом, нами предпринята попытка оценить эффективность двукратной смены антибиотиков.

Ключевые слова: острый панкреатит, антибактериальная терапия, панкреонекроз, деструктивный панкреатит, антибиотики.

заболевания. Тяжесть течения панкреатита делает его ярко выраженным примером критического состояния. При инфицировании поджелудочной железы, с развитием гнойно-септических осложнений, процент смертности увеличивается до 50-85\% [2,3]. Вместе с тем некоторые механизмы реализации патологических процессов не установлены [2,3], а число больных с деструктивными формами острого панкреатита постоянно растет [4,5].

Одной из отличительных особенностей течения острого панкреатита служит быстрый переход воспалительного процесса на системный уровень. Некроз поджелудочной железы приводит к выбросу большого количества продуктов распада ткани. Установлено, что ферментемия, медиаторы воспаления и продукты рас- 
пада способствуют возникновению синдрома системной воспалительной реакции. Последний и обуславливает тяжесть течения и прогноз острого панкреатита $[4,5,6]$.

Установлено, что замедление кровотока в тканях поджелудочной железы и увеличение вязкости крови способствует развитию и прогрессированию гипоксии $[4,5,6]$. Вместе с тем гипоксия приводит к деструктивным изменениям ткани поджелудочной железы [7]. Нарушение в системе гемостаза и расстройство микроциркуляции вызывают прогрессирование панкрернекроза [7]. Таким образом, формируется замкнутый порочный круг, который усугубляет течение деструктивных изменений [7]. В свою очередь эндогенная интоксикация способствует угнетению иммунной системы, что благоприятно сказывается на распространение системного воспалительного процесса и развитию гнойно-септических осложнений $[8,9]$.

Большинство авторов полагают, что эффективность лечения острого панкреатита зависит от своевременной постановки диагноза и адекватного лечения. Вместе с тем ранняя диагностика острого панкреатита представляет трудную задачу. Установлено, что количество ошибок на догоспитальном этапе и при первичном клиническом осмотре больного в стационаре составляет 50-70\%. Определенные трудности представляет и диагностика деструктивных форм острого панкреатита. Анализ данных литературы свидетельствует о том, что диагностика острого панкреатита должна быть комплексной и включать в себя методы инструментальной и лабораторной диагностики $[4,5,6]$.

В настоящее время хирурги продолжают дискутировать о выборе наиболее рационального метода лечения острого панкреатита $[4,5,6]$. По мнению большинства авторов, консервативная терапия эффективна у 75-85\% больных. Вместе с тем оперативное вмешательство необходимо выполнять при различных гнойных осложнениях. Необходимо отметить, что ранние операции на высоте эндогенной интоксикации и шокового состояния способствуют высокой летальности в послеоперационном периоде. Не стоит забывать, что недостаточная консервативная терапия может способствовать развитию гнойных осложнений с прогрессированием некроза ткани поджелудочной железы и нарастанием явлений полиорганной недостаточности [7,8,9]. В настоящее время существуют высокотехнологичные методы медицинской визуализации поджелудочной железы (УЗИ и МСКТ с трехмерным изображением, лапароскопия), которые позволяют определить степень тяжести патологического процесса и спрогнозировать течение острого панкреатита.[7,8,9].

Установлено, что для панкреонекроза, в основе которого лежит местная воспалительная реакция на фер- ментную агрессию, свойственно ранее развитие органных нарушений $[5,6,7]$. Системная воспалительная реакция и полиорганная недостаточность при остром тяжелом панкреатите определяют тяжесть состояния больных, прогноз заболевания и выбор оптимальной тактики лечебных мероприятий $[3,7,8]$. Вместе с тем в лечении острого панкреатита важна динамическая оценка степени тяжести состояния больного в ходе комплексного лечения $[2,3,7,8,9]$. На сегодняшний день существую различные клинико-лабораторные системы-шкалы: Ranson, Glasgow, APACHE II, MODS, SOFA, а также биохимические системы оценки: С-реактивный белок, интерлейкины, эластаза нейтрофилов. $[7,8,9]$.

В виду того, что в анализируемой литературе нет данных об адекватной антибактериальной терапии у пациентов с острым деструктивным панкреатитом, нами предпринята попытка оценить эффективность двукратной смены антибиотиков.

\section{பель работы}

Оценить эффективность двукратной смены антибактериальной терапии у больных с деструктивными формами острого панкреатита, которые получали лечение на базе хирургического отделения ГУЗ ГКБ № 1 города Чита.

\section{Материалы и метолы}

Произведен ретроспективный анализ карт стационарных больных с диагнозом «Острый панкреатит. Панкреонекроз», находящихся на лечении в ГУЗ ГКБ № 1 отделении хирургии за период 2018 г. $(n=80)$, получающие консервативное лечение согласно рекомендациям POX. Пациенты были разделены на 2 клинические группы:

1группа - пациенты, которым проводилась антибактериальная терапия Pul. Ceftriaxoni 2gr в/в капельно на физиологическом растворе - 12 дней и 2 группа -пациентов, которым проводилась антибактериальная терапия Pul. Ceftriaxoni 2gr в/ в капельно на физиологическом растворе $\mathrm{x} 1$ раз - 5 дней, после Sol. Cefopizasoni sulboctami 2gr на физиологическом растворе в/в капельно х2 раза - 7 дней.

\section{Результаты}

По результатам анализа установлено, что у пациентов второй группы в сравнении с пациентами первой группы отмечается значительное уменьшение койко-дней. Так у пациентов первой группы продолжительность госпитализации составила в среднем 20 дней $(p<0,05)$, а у второй 12 дней $(\mathrm{p}<0,05)$ (рис. 1). 


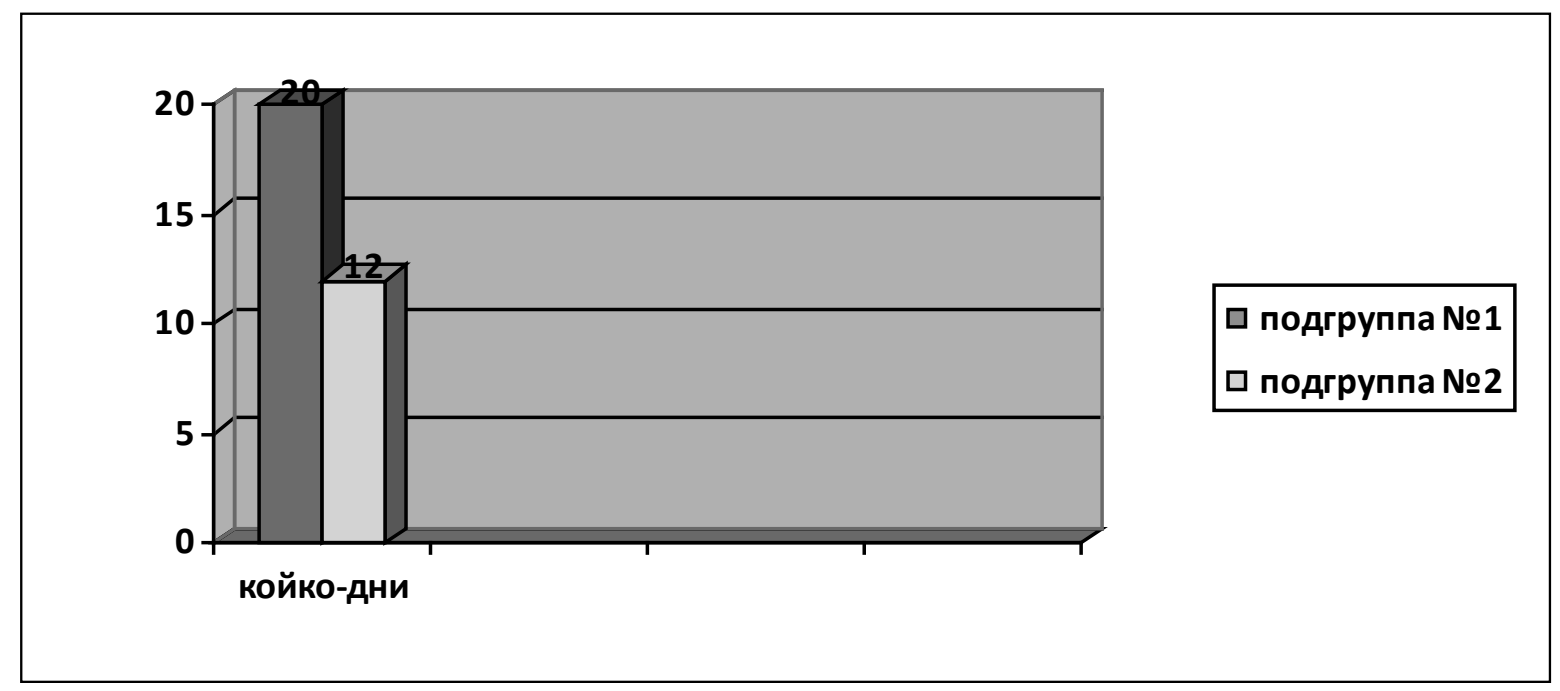

Рис. 1. Продолжительность госпитализации

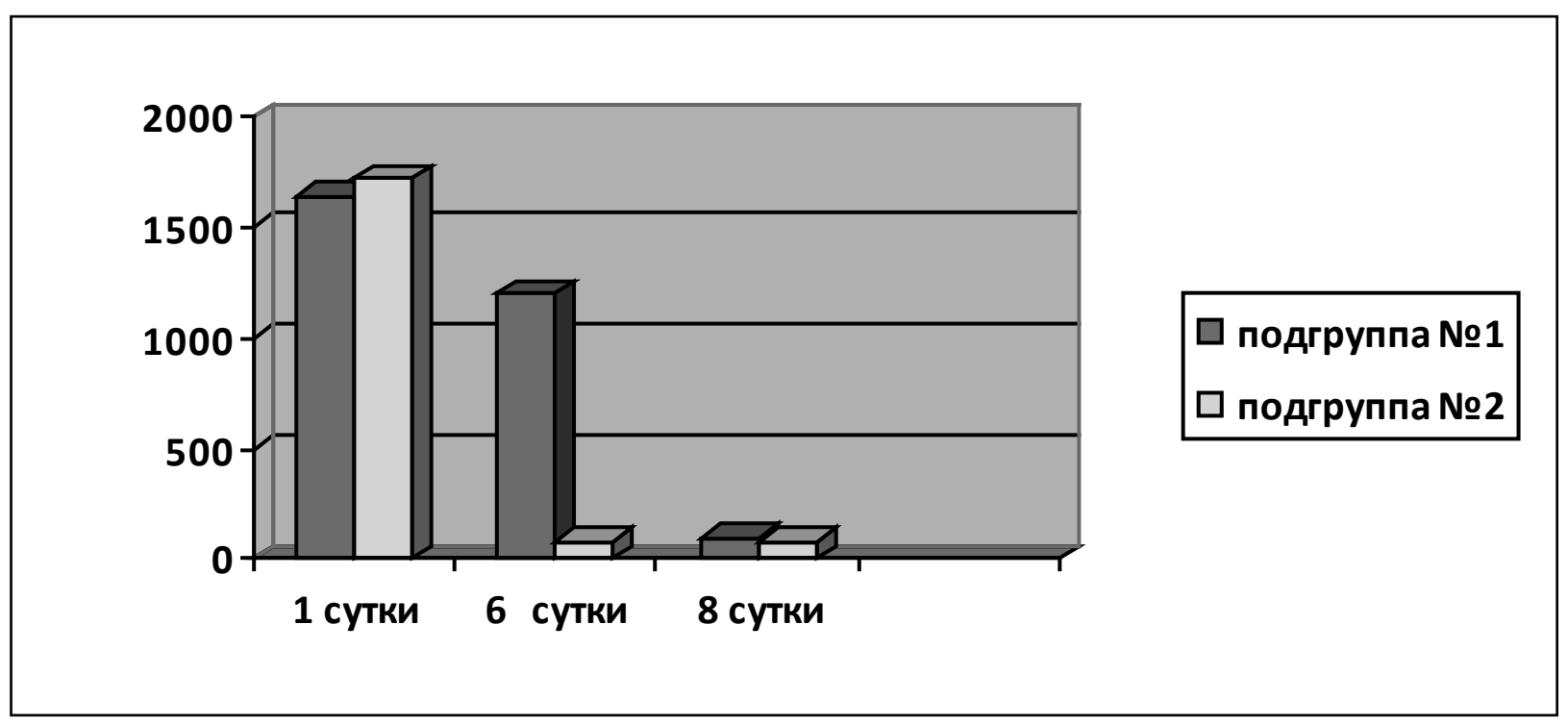

Рис. 2. Активность амилазы

Вместе с тем необходимо отметить, что в кротчайшие сроки отмечается уменьшение активности амилазы в периферической крови: в первой группе нормальное значение амилазы достигается на 8 сутки $(p<0,05)$, во второй на 6 сутки $(p<0,05)$ (рис. 2).

Выявлено уменьшение количества ряда гнойных осложнений острого панкреатита (плевритов, абсцессов сальниковой сумки, флегмон забрюшинного пространства). Так если в первой группе частота инфекционных осложнений достигает $30 \%(p<0,05)$, то во второй группе $5 \%(p<0,05)$. Вместе с тем по результатам УЗИ и данным КТ органов брюшной полости деструктивные изменения в ткани поджелудочной железы ограничиваются в первой группе на 12 сутки $(p<0,05)$, а во второй группе на 7 сутки $(p<0,05)$ (Рисунок 3$)$.

\section{Выво $\triangle \mathrm{b}$}

1. При двукратной смене антибактериальной терапии уменьшаются сроки лечения.

2. Во второй группе регистрируется более быстрое снижение показателей амилазы и ограничение процесса деструкции поджелудочной железы.

3. Отмечается уменьшение количества воспалительных осложнений в 6 раз во второй группе. 


\section{ЛИТЕРАТУРА}

1. Савельев В.С., Филимонов М. И., Бурневич С. 3. Панкреонекрозы.- М., МИА, 2008-264с.

2. Савельев В.С., Филимонов М. И., Бурневич С. 3. Острый панкреатит. / Национальное руководство по хирургии. — 2009, т. 2.— c. $196-229$.

3. Протоколы обследования и лечения больных острым панкреатитом. Методические рекомендации под редакцией Ю. Л. Шевченко. - М., 2010-21с.

4. убышкин, В. А. Острый панкреатит // Тихоокеанский медицинский журнал.— 2009., № 2.—C. 48-52.

5. Дюжева Т.Г., Терновой С. К., Джус Е. В., Шефер А. В., Гальперин Э. И. Мультиспиральная компьютерная томография в диагностике острого панкреатита и локальных парапанкреатических осложнений. // Медицинская визуализация. — 2011., № 4.—C. 137-139.

6. Дюжева Т. Г., Джус Е. В., Шефер А. В., Ахаладзе Г. Г., Чевокин А. Ю., Котовский А. Е., Платонова Л. В., Гальперин Э. И. Конфигурация некроза поджелудочной железы и дифференцированное лечение острого панкреатита. // Анналы хирургической гепатологии. — 2013., Т. 18, № 1.—C. 92-102.

7. Багненко С. Ф., Савелло В. Е., Гольцов В. Р. Лучевая диагностика заболеваний поджелудочной железы: панкреатит острый / Лучевая диагностика и терапия в гастроэнтерологии: национальное руководство (гл. ред. тома Г. Г. Кармазановский). — М.: ГЭОТАР-Медиа, 2014.—C. 349-365.

8. Dellinger E. P., Forsmark C. E., Layer P., Levy P., Maravi-Poma E., Petrov M. S., Shimosegawa T., Siriwardena A. K., Uomo G., Whitcomb D. C., Windsor J. A. Determinant_ based classification of acute pancreatitis severity: an international multidisciplinary consultation. Ann. Surg. 2012; 256 (6): 875-880.

9. Freeman M. L., Werner J., van Santvoort H. C., Baron T. H. Besselink M. G., Windsor J. A., Horvath K. D., van Sonnenberg E. Bollen T. L., Vege S. S. Interventions for Necrotizing Pancreatiti. Summary of Multidisciplinary Consensus Conference. Pancreas. 2012; 41 (8): 1176-1194.

( ) Яшнов Алексей Александрович ( alexyashnov@mail.ru ), Коновалова Ольга Геннадьевна ( konovalovaolgagen@yandex.ru ), Ханина Юлия Сергеевна ( assistenty@yandex.ru, Яшнова Надежда Борисовна, Пассонен Екатерина Юрьевна

Журнал «Современная наука: актуальные проблемы теории и практики»

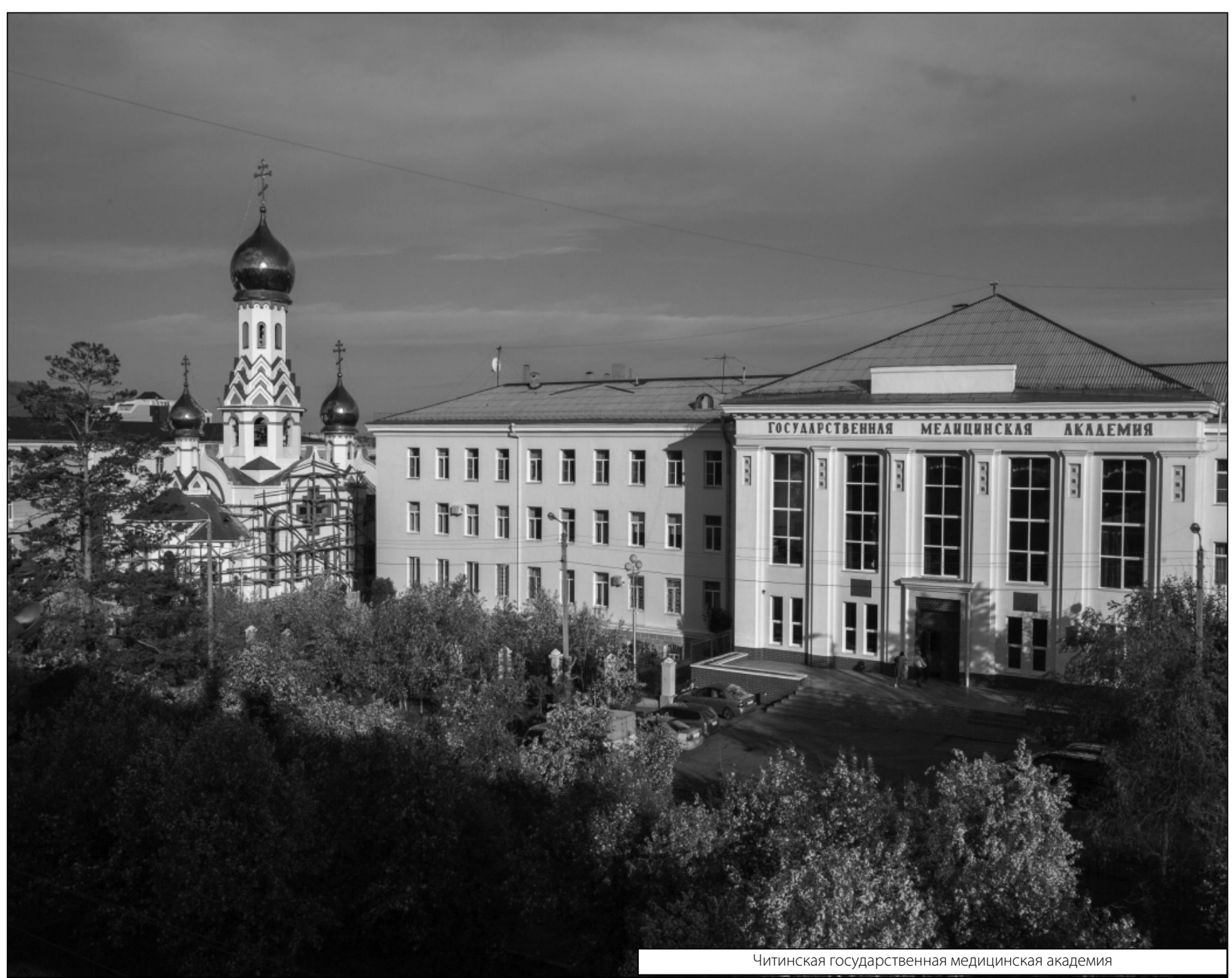

